Pathophysiology of Haemostasis and Thrombosis

\title{
Lack of Plasminogen Activator Inhibitor-1 Enhances the Preventive Effect of DX-9065a, a Selective Factor Xa Inhibitor, on Venous Thrombus and Acute Pulmonary Embolism in Mice
}

\author{
En Shua,b Hiroyuki Matsuno ${ }^{a}$ Akira Ishisaki $^{a}$ Yasuo Kitajimab \\ Osamu Kozawa ${ }^{a}$ \\ Departments of aPharmacology and bermatology, Gifu University School of Medicine, Gifu, Japan
}

\author{
Key Words \\ Fibrinolytic components - Thromboembolism • \\ Pulmonary embolism • Venous thrombus
}

\begin{abstract}
We have studied the physiological effects of DX-9065a, a selective factor $\mathrm{Xa}(\mathrm{FXa})$ inhibitor, and heparin in experimental venous thrombus and acute pulmonary embolism. Moreover, the effects of these compounds were also evaluated under the condition of plasminogen activator inhibitor-1 (PAl-1) deficiency. A thrombus was induced in the murine femoral vein. The compounds prolonged the time to occlusion in a dose-dependent manner. Pulmonary embolism was induced by continuous induction of venous thrombi in the left jugular vein. The mortality of mice increased time-dependently. Histological evidence of thromboembolism in the lung was obtained in all mice. Treatment with DX-9065a, but not heparin, reduced the mortality at $6 \mathrm{~h}$ after initiation of venous thrombi. In separate experiments, pulmonary thromboembolism was induced in PAI-1 knockout mice. The mortality in PAI-1 knockout mice was reduced compared with that of wild-type mice. Moreover, when DX-
\end{abstract}

9065a was administered to PAl-1 knockout mice with pulmonary thromboembolism, mice survived well without marked bleeding. These findings indicate that the dual inhibition of coagulation FXa and PAI-1 could be beneficial in the treatment of acute pulmonary embolism.

Copyright $\odot 2004$ S. Karger AG, Basel

\section{Introduction}

Venous thrombosis and pulmonary embolism are important causes of morbidity and mortality in vascular diseases [1]. Survivors of venous thromboembolism are known to be at risk of recurring thrombosis, postphlebitic syndrome, and pulmonary hypertension [2]. Additionally, it is known that the economy class syndrome is caused by deep vein thrombosis [3]. The thrombolytic resistance of venous thrombi is different from that of arterial thrombi since the physical characteristics of thrombi, such as size, retraction and exposure to blood flow, may affect their lysis. Heparin and low-molecular-weight heparin have been used clinically as standard anticoagulants for the prevention of venous thromboembolism. Although heparin decreases new thrombus formation, clinical studies

\begin{tabular}{ll}
\hline KARGER & ( 2004 S. Karger AG, Basel \\
1424-8832/04/0334-0206\$21.00/0 \\
$\begin{array}{l}\text { Fax +4161306 12 34 } \\
\begin{array}{l}\text { E-Mail karger@karger.ch } \\
\text { www.karger.com }\end{array}\end{array}$ & $\begin{array}{l}\text { Accessible online at: } \\
\text { www.karger.com/pht }\end{array}$
\end{tabular}

Hiroyuki Matsuno, $\mathrm{PhD}$

Department of Pharmacology, Gifu University School of Medicine

Tsukasa-machi 40

Gifu 500-8705 (Japan)

Tel. +8158267 2231, Fax +8158267 2959, E-Mail leuven@cc.gifu-u.ac.jp 
indicate that there is little early endogenous lysis of large thrombi that often exist at the time of diagnosis in patients with venous thromboembolism [4]. Several studies have examined the effects of plasminogen activators (PAs) in patients with venous thromboembolism [5-7]. Compared with heparin alone, PAs cause a significant increase in lysis of venous thromboemboli, but patients are frequently left with large amounts of residual thrombus in the lungs or deep veins immediately after therapy [8]. These findings showed that it is possible that a lack of plasminogen activator inhibitor-1 (PAI-1) could amplify the effect of anticoagulant compounds. Indeed, PAI-1 is well known as a potent inhibitor of PAs, such as tissuetype PA and urokinase-type PA. An elevation of PAI-1 levels in circulation has been reported to be a risk factor for pulmonary embolism $[9,10]$. Both clinical and experimental studies over the past few years have suggested the importance of PAI-1 in thrombosis and the maintenance of systemic vascular hemostasis [11, 12]. Experiments with transgenic mice deficient in PAI-1 support a role of this serpin in pulmonary fibrosis occurring after inflammatory injury [13]. High levels of PAI-1 were observed in endothelial cells and vascular smooth muscle cells within chronic nonresolving vascular thrombi [14]. We previously reported on the role of fibrinolytic components in arterial thrombus formation induced by the photochemical reaction between a photosensitive dye compound, rose bengal, and green light $(540 \mathrm{~nm})$ using tissue-type PA- and urokinase-type PA-deficient mice [15]. These results clearly indicated that a lack of either fibrinolytic component affects the development and removal of arterial thrombus formation.

In a separate series of responses, vascular injury is well known to activate the coagulation cascade (through the intrinsic or tissue factor pathway) by generating factor Xa (FXa). The prothrombinase complex forms on all kinds of activated cell surfaces, such as platelets and endothelial cells. This enzyme catalyzes the conversion of prothrombin to thrombin. Recently there has been a report on a highly selective nonpeptide inhibitor of FXa, DX-9065a, and its antithrombotic efficacy has been demonstrated in several animal models of acute arterial thrombus [16]. Additionally, our published report showed that DX9065a significantly affected the development of arterial thrombus formation in mice [17]. Therefore, in the present study, we applied our system to the production of thrombi in the jugular vein with consequent pulmonary embolism and evaluated the effect of a selective FXa inhibitor compared with heparin. We also investigated the role of PAI-1 using PAI-1 knockout (PAI-1-1-) mice.

\section{Materials and Methods}

\section{Animals}

C57BL/6J mice (SLC, Japan) weighing 26-30 g were selected and fed a standard chow (RC4, Oriental Yeast, Japan). Deficient mice were generated by homologous recombination in embryonic stem cells, as described previously [18]. All experiments were performed in accordance with the institutional guidelines.

\section{Reagents}

DX-9065a was a kind gift from Daiichi (Tukuba, Japan). PAI-1 and the other chemical substances were obtained from Cosma Bio (Tokyo Japan) and Sigma-Aldrich Chemical Co. (St. Louis, Mo., USA), respectively.

\section{Production of Endothelial Injury}

The experimental procedure to induce an endothelial injury has previously been described in detail [15]. Mice were anesthetized by intraperitoneal injection of $44 \mathrm{mg} / \mathrm{kg}$ sodium pentobarbital. In brief, the right jugular vein, the left femoral vein and the right femoral artery were exposed. Catheters (Natume, Tokyo, Japan) were connected to the right jugular vein and to the right femoral artery for the injection of rose bengal $(30 \mathrm{mg} / \mathrm{kg})$ and for monitoring blood pressure and pulse rate using a pressure transducer (AP601G Nihon Koden, Tokyo, Japan) during experiments on day 0 . Blood flow in the carotid artery was continuously monitored using a Doppler flow probe (model PDV-20, Crystal Biotech Co., Tokyo, Japan) positioned proximally to the injured area of the femoral vein. Irradiation by green light $(540 \mathrm{~nm})$ proximal to the flow probe was started and then rose bengal was injected as a bolus 10 min after the observation of control blood flow. The irradiation was continued for $15 \mathrm{~min}$ after the injection of rose bengal. This procedure results in the destruction of endothelial cells in the irradiated area by oxygen radicals induced by the photochemical reaction between rose bengal and green light [19]. The flow probe was removed after the observation period. An occlusive thrombus formation was judged to occur when blood flow was zero. Our previous histological observations have revealed that a plateletrich thrombus including fibrin was formed when the blood flow was zero [15].

\section{Effects of DX-96065a and Heparin on Venous Thrombus}

Mice were divided into seven groups: control group $(\mathrm{n}=12)$, three groups treated with DX-9065a at doses of $1.0,3.0$ or $10.0 \mathrm{mg} / \mathrm{kg}$ $(\mathrm{n}=12 \mathrm{each})$ and three groups treated with heparin at doses of 30 , 100 or 300 units $/ \mathrm{kg}(\mathrm{n}=12 \mathrm{each})$. Intravenous injection of each compound was started $5 \mathrm{~min}$ before the initiation of endothelial injury. Venous blood flow was continuously monitored for $30 \mathrm{~min}$. The experimental protocol is shown schematically in figure 1a.

Induction of Pulmonary Embolism by Venous Thrombosis

The experimental procedure to induce an endothelial injury has previously been described in detail [19]. Mice were anesthetized by intraperitoneal injection of $44 \mathrm{mg} / \mathrm{kg}$ sodium pentobarbital. In brief, the left jugular vein, the left femoral vein and the right femoral artery were exposed and catheters (Natume, Tokyo, Japan) were connected to the left femoral vein for the infusion of rose bengal and to the right femoral artery for monitoring blood pressure and pulse rate using a pressure transducer (AP601G, Nihon Koden, Tokyo, Japan). Rose bengal $(25 \mathrm{mg} / \mathrm{kg})$ was continuously infused for 20 min using an infusion pump (STC-523, TERMO, USA) at a constant rate of $1.0 \mathrm{ml} / \mathrm{h}$. 
a

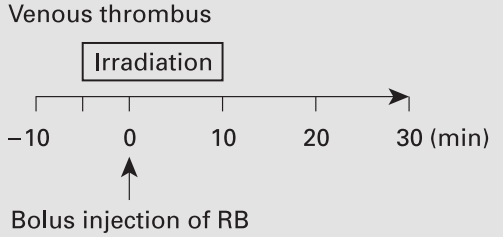

b Pulmonary embolism

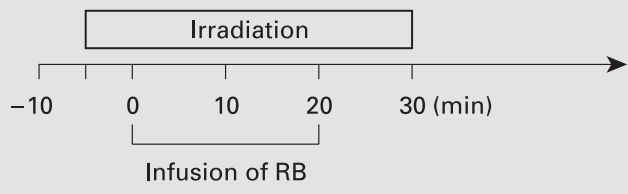

Fig. 1. Experimental protocols. a Venous thrombus in femoral vein was induced by endothelial injury due to a photochemical reaction between a photosensitive dye compound, rose bengal (RB), and the irradiation of green light $(540 \mathrm{~nm})$. Blood flow was continuously monitored $10 \mathrm{~min}$ before a bolus injection of RB and maintained for the next $30 \mathrm{~min}$. b Pulmonary embolism was induced by continuous induction of venous thrombus in jugular vein by endothelial injury due to photochemical reaction. RB was infused for 20 min. Irradiation of light was started 5 min before the infusion of RB and continued for the next $30 \mathrm{~min}$.

Irradiation with green light $(540 \mathrm{~nm})$ of the jugular vein was started $5 \mathrm{~min}$ before the start of infusion and continued for the next $35 \mathrm{~min}$. The left femoral vein and right femoral artery were ligated after the connected catheters were removed. After recovery from anesthesia, the animals were kept in individual cages and fed standard chow (RC4, Oriental Yeast, Japan).

\section{Effects of DX-96065a and Heparin on Acute Pulmonary \\ Embolism}

Mice were divided into three groups: a control group $(n=30)$, two groups treated with DX-9065a at a dose of $3.0 \mathrm{mg} / \mathrm{kg}(\mathrm{n}=30)$ or with heparin at a dose of 300 units $/ \mathrm{kg}(\mathrm{n}=30)$. Each compound was intravenously injected after the end of irradiation. After recovery from anesthesia, the animals were kept in individual cages and fed standard chow (RC4, Oriental Yeast, Japan). The experimental protocol is schematically shown in figure $1 b$.

\section{Lung Histopathology}

In separate experiments, mice of each group $(n=3)$ were sacrificed by the injection of an overdose of pentobarbital $1 \mathrm{~h}$ after the induction of venous thrombus. At the time of death, mice were exsanguinated and $2 \mathrm{ml}$ of phosphate-buffered saline (PBS) was injected into the right jugular vein to perfuse the lungs. The lungs were removed and inflated to total lung capacity with air injected via an angiocath placed in the trachea. Next, the lungs were transferred to $4 \%$ formaldehyde for $24 \mathrm{~h}$ and then to PBS. The lungs were embedded in paraffin and butterfly-shaped sections of 5- $\mu \mathrm{m}$ thickness were made. The sections were mounted on glass microscope slides and were stained with hematoxylin and eosin.

\section{Effect of PAI-1 on Pulmonary Embolism}

PAI-1 ${ }^{-/-}$mice $(\mathrm{n}=12)$ and their wild types $(\mathrm{n}=12)$ were used for the decision of survival ratio after initiation of pulmonary embolism. Pulmonary embolism was induced as described above by venous thrombosis. In order to define the effect of PAI-1 on acute pulmonary embolism, PAI-1 (30 ng/body) was continuously infused in PAI-1 ${ }^{-/}$ mice $(n=6)$ using an infusion pump. The infusion was started at the end of the irradiation and continued for the next $2 \mathrm{~h}$. In separate experiments, DX-9065a $(10.0 \mathrm{mg} / \mathrm{kg})$ or heparin $(300 \mathrm{units} / \mathrm{kg})$ was administered in PAI-1 ${ }^{-/-}$mice ( $n=6$, each group).

\section{Tail Bleeding Times in Mice Deficient in PAI-1}

Bleeding time was defined as described earlier [20]. At $1 \mathrm{~h}$ after the initiation of thrombi, a distal 2-mm segment of tail in each mouse was severed with a razor blade after anesthesia with pentobarbital. The tail was immediately immersed in $0.9 \%$ saline at $37^{\circ} \mathrm{C}$ with the tip of the tail $5 \mathrm{~cm}$ below the body. The bleeding time was defined as the time required for cessation of blood overflow (stop of blood spread in saline).

\section{Statistics}

All data are presented as the mean \pm SEM. The statistical significance of the differences was determined by ANOVA followed by the Student-Newman-Keuls test. For the mortality at $2 \mathrm{~h}$ after the initiation of thrombus induction, the significance was determined by the $\chi^{2}$ test.

\section{Results}

\section{Acute Thrombus Formation}

The times to occlusion after initiation of endothelial injury of femoral vein in each group are shown in figure 2 . After the initiation of endothelial injury by the photochemical reaction, an occlusive thrombus was formed in control mice at an average of $11.1 \pm 1.4 \mathrm{~min}$. In mice treated with DX-9065a or heparin, the time to occlusion was prolonged dose-dependently. Especially, when the highest dose of DX-9065a $(10.0 \mathrm{mg} / \mathrm{kg})$ or heparin $(300$ units $/ \mathrm{kg}$ ) was used in mice, time to occlusion was statistically significantly prolonged as compared with that of the control groups (injection of saline).

\section{DX-9065a Decreases the Mortality after Acute Pulmonary Embolism}

Figure 3 shows the time-dependent alteration of the survival ratio in mice after the initiation of venous thrombosis. Thirty mice suffered from acute pulmonary thromboembolism, of which (56.7\%) survived for the next $1 \mathrm{~h}$. This ratio gradually decreased until $6 \mathrm{~h}$ after the initiation of venous thrombus $(43.3 \%$ at $6 \mathrm{~h})$. The survival ratio $(63.3 \%)$ of mice treated with DX-9065a $(\mathrm{n}=30)$ at $6 \mathrm{~h}$ was increased as compared with that of the control mice. In contrast, in mice treated with heparin $(n=30)$, the sur- 


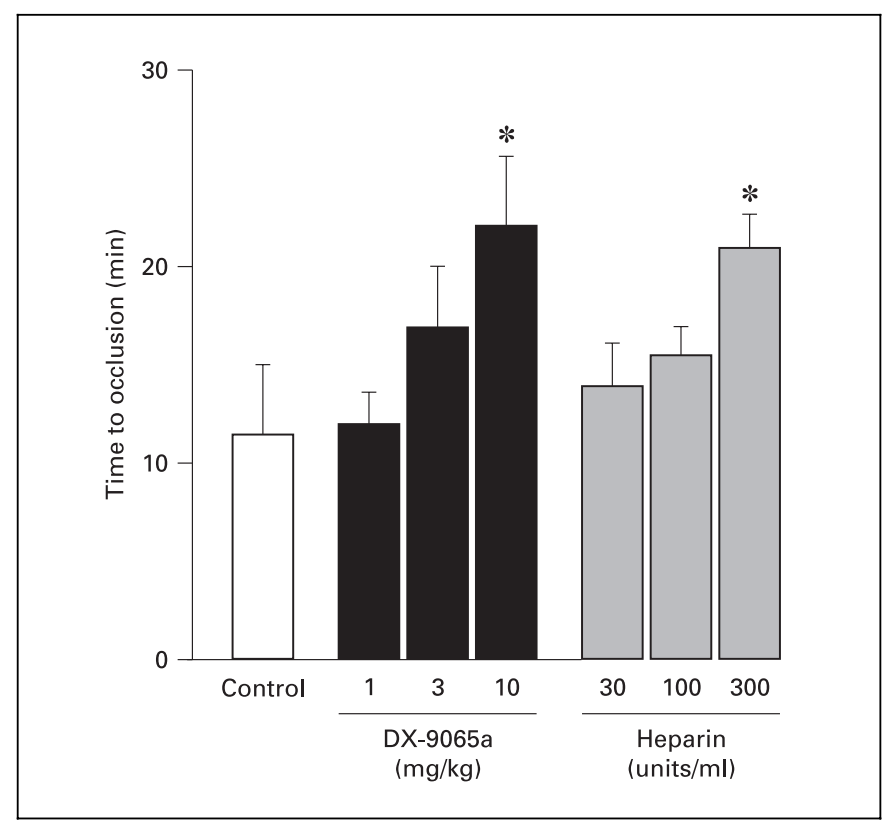

Fig. 2. Thrombus formation in the murine femoral vein. Time to occlusion represented as mean \pm SEM in each experiment. Control group, groups treated with DX-9065a and groups treated with heparin are shown. $* \mathrm{p}<0.05$ versus control group.

vival ratio $(80.0 \%)$ was increased at $1 \mathrm{~h}$ after the initiation of pulmonary thromboembolism. However, the survival ratio immediately decreased during the next $2 \mathrm{~h}$ and it did not change significantly as compared with that of control mice at the end of the observation period. All mice that died showed serious gasping and no significant change of the heart rate or blood pressure before the start of gasping. At the end of the observation period $(8 \mathrm{~h}$ after the initiation of venous thrombi), the survival ratio of each group was shown in table 1. Treatment with DX-9065a significantly increased the survival ratio as compared with that of the control group or group treated with heparin.

\section{Effect of PAI-1 on Acute Pulmonary Embolism}

Twelve wild-type mice suffered from acute pulmonary thromboembolism, of which $5(41.7 \%)$ survived for the following $6 \mathrm{~h}$. This ratio was almost the same as that of control mice $(\mathrm{C} 57 \mathrm{BL} / 6 \mathrm{~J})$. The survival ratio of mice deficient in PAI-1 (58.3\%) was increased as compared with that of the wild-type mice. This advantage was deleted by the treatment with PAI-1 in PAI-1/- mice (data not shown). All mice that died showed serious gasping and no significant change of heart rate or blood pressure before the start of gasping. On the other hand, PAI-1-deficient

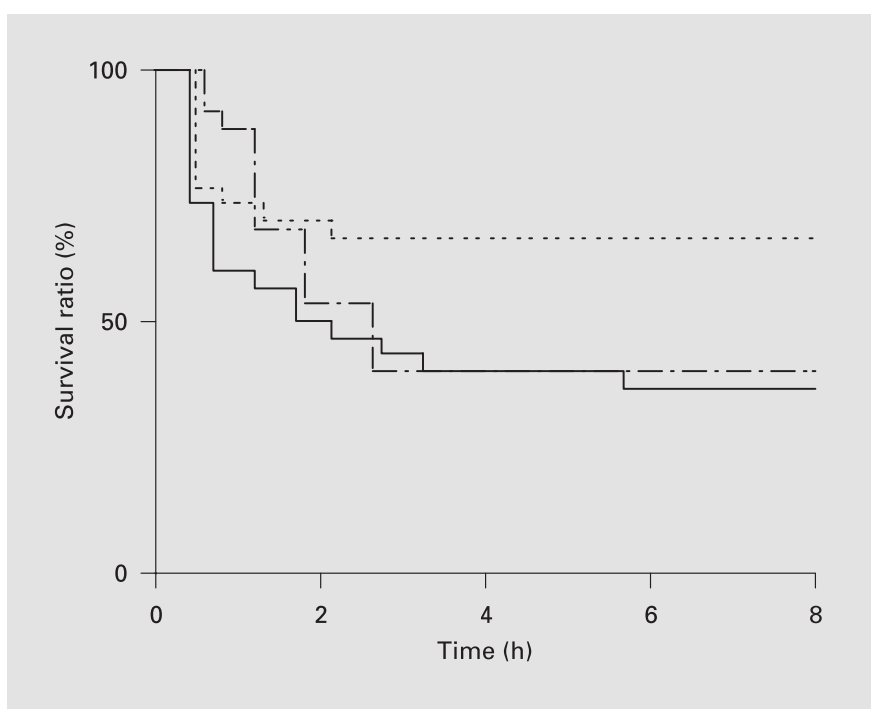

Fig. 3. Change of survival ratio after the initiation of thromboembolism. Mice were divided into three groups: control group $(-, \mathrm{n}=$ 30), a group treated with DX-9065a $(---, \mathrm{n}=30)$ and a group treated with heparin $(-\cdot-, \mathrm{n}=30)$. Six hours after the initiation of pulmonary thromboembolism, the survival ratios of the control group, the group treated with DX-9065a $(3.0 \mathrm{mg} / \mathrm{kg})$ and the group treated with heparin (300 units/ml) were $36.7,66.7$ and $46.7 \%$, respectively.

Table 1. Survival ratio after acute pulmonary embolism

\begin{tabular}{ll}
\hline & Survived/total \\
\hline Control & $12 / 30$ \\
DX-9065a (3.0 mg/kg) & $20 / 30^{*}$ \\
Heparin (300 units $/ \mathrm{ml})$ & $13 / 30$ \\
\hline
\end{tabular}

$* \mathrm{p}<0.05$ versus control group.

mice with DX-9065a $(3.0 \mathrm{mg} / \mathrm{kg})$ survived well within $8 \mathrm{~h}$ following the start of the acute pulmonary thromboembolism induction (83.3\%) even if the mortality of PAI-1/mice with heparin did not change as compared with that of mice deficient in PAI-1 without anticoagulant compounds. Survival ratios are shown in table 2. Histological observations clearly supported these results (fig. 5). Typical microphotographs show a normal lung of a sham-operated wild-type (PAI-1 ${ }^{+/+}$) mouse (fig. 5a) or PAI-1 $1^{-/}$ mouse (fig. 5b), a lung after pulmonary embolism in a PAI-1 ${ }^{+/+}$(fig. 5c) or PAI-1 ${ }^{-/-}$mouse (fig. 5d) and a lung after pulmonary embolism with DX-9065a in a PAI-1 $1^{+/+}$ 


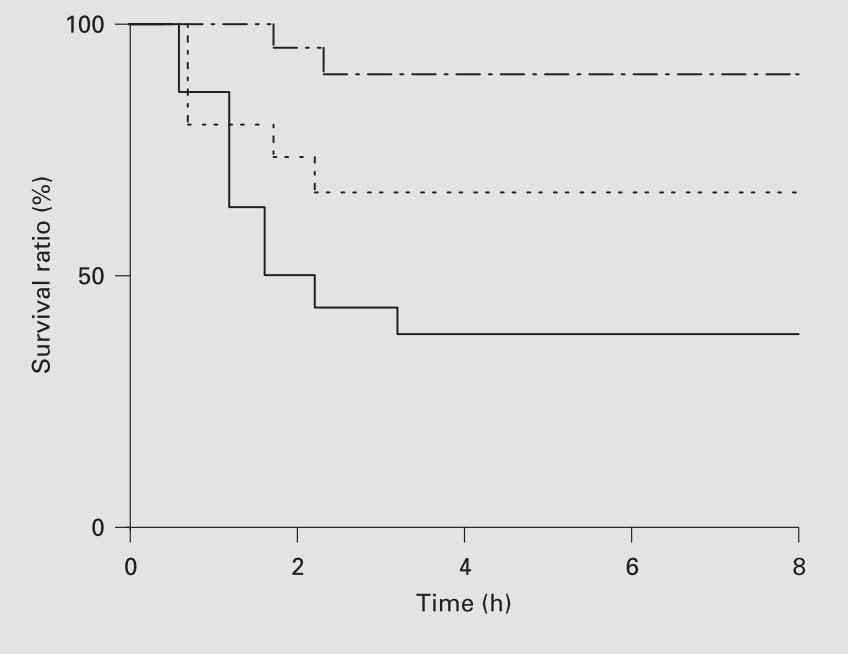

Fig. 4. Change of survival ratio after the initiation of thromboembolism in PAI-1 knockout mice. PAI-1 knockout (PAI-1 $\left.{ }^{-/-}\right)$and wildtype $\left(\mathrm{PAI}-1^{+/+}\right)$mice were used. Survival ratio of PAI- $1^{+/+}$mice $(-)$ decreased time-dependently and it was almost the same as the control group (fig. $3,-$ ) at $6 \mathrm{~h}$ after the initiation of pulmonary thromboembolism. Survival ratio of PAI-1---- mice (- - -) was increased $(58.3 \%)$ as compared with that of PAI- $1^{+/+}$mice $(41.7 \%)$. The treatment with DX-9065a at a dose of $3.0 \mathrm{mg} / \mathrm{kg}$ in PAI-1-/- mice (---) markedly improved the survival ratio.

Table 2. Survival ratio after acute pulmonary embolism in mice deficient in PAI-1

\begin{tabular}{|c|c|}
\hline & Survived/tota \\
\hline PAI- $1^{+/+}$ & $5 / 12$ \\
\hline PAI-1 $1^{-/-}$ & $7 / 12$ \\
\hline PAI-1 ${ }^{-/-}+$DX-9065a $(3.0 \mathrm{mg} / \mathrm{kg})$ & $10 / 12^{*}$ \\
\hline
\end{tabular}

$* \mathrm{p}<0.05$ versus PAI- $1^{+/+}$group.

Table 3. Bleeding time

\begin{tabular}{lll}
\hline & PAI-1 $^{-/-}$ & PAI- $^{+/+}$ \\
\hline Control & $55.9 \pm 4.7$ & $59.5 \pm 8.9$ \\
DX-9065a (3.0 mg/kg) & $61.3 \pm 4.4$ & $57.1 \pm 7.2$ \\
Heparin (300 units $/ \mathrm{kg})$ & $65.2 \pm 8.4$ & $88.6 \pm 9.4^{*}$
\end{tabular}

$* \mathrm{p}<0.05$ versus control group. (fig. 5e) or PAI- ${ }^{-/}$mouse (fig. 5f). In PAI-1 ${ }^{-/-}$mice, thrombi were observed in many parts of the pulmonary micro- and large vessels (fig. 5c). When DX-9065a was administered in $\mathrm{PAI}-1^{+/+}$mice after the initiation of thromboembolism, occlusive thrombi were not observed in large vessels. However, there were many thrombi in microvessels. In contrast, only a few thrombi were detected in the lung of a PAI-1 ${ }^{-/-}$mouse (fig. 5d) as compared with that of a PAI- $1^{+/+}$mouse (fig. $5 \mathrm{c}$ ). Moreover, administration of DX-9065a much decreased thrombus formation in the lungs of a PAI-1/- mouse and occlusive thrombi in vessels were rarely observed (fig. $5 f$ ).

\section{Bleeding Time}

Tail bleeding time is given in table 3. No significant differences in tail bleeding time were observed between gene-deficient and wild-type mice. However, when heparin (300 units $/ \mathrm{kg}$ ) was infused, the bleeding time was prolonged in both knockout and wild-type mice. On the other hand, the treatment with DX-9065a slightly prolonged the bleeding time in PAI-1-/- mice, but not in PAI- $1^{+/+}$ mice.

\section{Discussion}

The present study was carried out to evaluate the effects of DX-9065a, a selective FXa inhibitor, or heparin on a murine model of venous thrombus and acute pulmonary embolism as a consequence of venous thrombosis. Additionally, we also investigated the role of PAI-1 in acute pulmonary embolism and antithrombotic effects of DX-9065a or heparin in PAI-1 ${ }^{-/-}$mice.

It is well known that the cascade of coagulation and fibrinolysis plays a key role in the development and removal of thrombi in vivo. The activated serine protease FXa is the key enzyme at the convergent point of the intrinsic and tissue factor pathways of coagulation. FXa forms a prothrombinase complex with factor $\mathrm{Va}$, calcium and phospholipid to produce thrombin. Therefore, inhibition of FXa could more effectively influence the anticoagulant activity than inhibition of thrombin. A highly selective nonpeptide inhibitor of FXa has been reported [9] that showed antithrombotic effects in vivo [21]. In the present study, pretreatment with either DX-9065a or heparin prevented the development of venous thrombus formation in a dose-dependent manner. This finding was in agreement with previous reports: the inhibition of thrombin generation certainly reduced the development of venous thrombosis. 

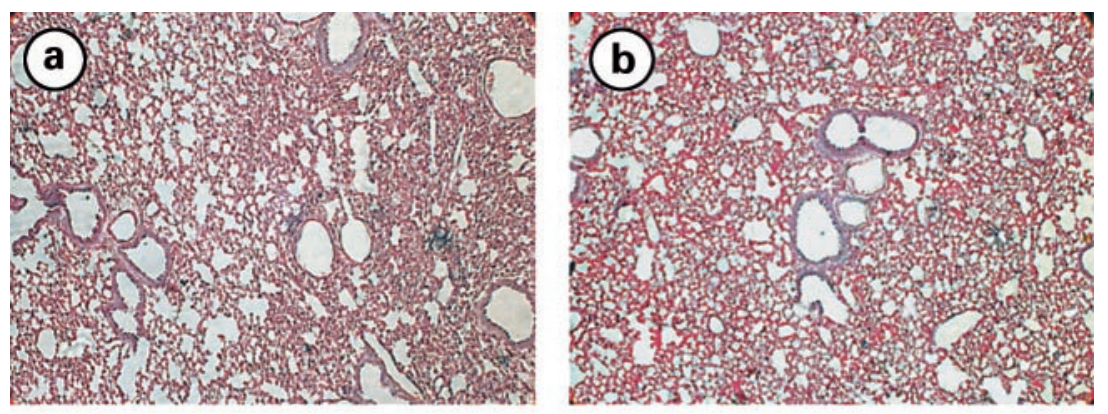

Fig. 5. Histological observation of the murine lung. Microphotographs of lung sections show a lung of PAI- $1^{+/+}(\mathbf{a}, \mathbf{c}, \mathbf{e})$ and PAI- $1^{-/-}$mice $(\mathbf{b}, \mathbf{d}, \mathbf{f})$ without the initiation of venous thrombosis $(\mathbf{a}, \mathbf{b})$, with pulmonary thromboembolism after the initiation of venous thrombosis without DX-9065a (c, d) and with DX-9065a at a dose of $3.0 \mathrm{mg} / \mathrm{kg}(\mathbf{e}, \mathbf{f})$. a, b Thrombi were not observed in any areas of the lung. c There were extensive thrombi throughout all areas of the lung. d Thrombi were observed in several parts of the lung. e Thrombi were observed in the small vessels of the lung, but not in the large ones (asterisks). f Thrombi were infrequently seen in the lung. They only remained in some of the large vessels (asterisk). Bar $=100 \mu \mathrm{m}$.
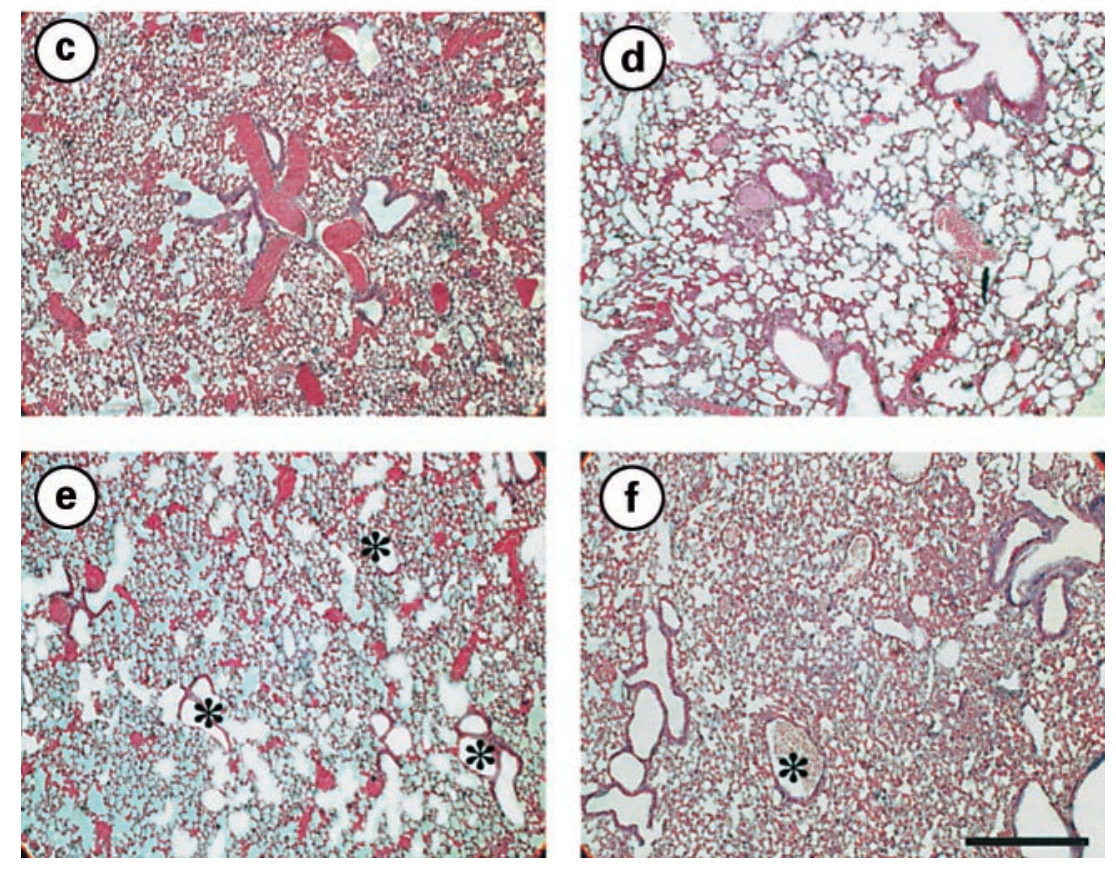

Several investigations of experimental pulmonary embolism using mice have been reported [22, 23]. However, experimental pulmonary embolism was mainly induced by the injection of radiolabeled clots via the jugular vein where these clots caused damage restricted to the lungs of the mice. These clots are not the same as those observed in pulmonary embolism in vivo since they were developed completely in vitro and were then inserted into the circulation. Indeed, pulmonary emboli appear to originate from fragmentation of a propagating thrombus deep in the venous system [24]. In the present experiments, thrombus formation was induced by venous endothelial injury after which embolism was observed in the lung. Our previous data clearly showed that thrombus formation with activated platelets (adhesion and aggregation), fibrin nets and other blood elements developed within minutes after initiation of endothelial injury by photo- chemical reaction [15, 19]. Several cycles of growth and disappearance were observed, indicating that emboli were likely formed [6]. We adapted this model for further study of physiological pulmonary embolism and evaluation of antithrombotic compounds. We photochemically induced a thrombus in the murine jugular vein, which caused a milder and more reproducible venous thrombosis. Indeed, we succeeded in establishing a suitable pulmonary embolism following the development of venous thrombus in mice: a mortality of $43.3 \%$ was observed $1 \mathrm{~h}$ after initiation of venous thrombosis. The mortality was gradually increased until $6 \mathrm{~h}$ after initiation of thrombi. When mice were dying after the development of venous thrombi, serious gasping was invariably observed. Moreover, blood pressure and heart rate did not significantly change before the marked gasping. These findings indicated that continuous induction of venous thrombi in the 
jugular vein induced pulmonary embolism in mice and these embolisms were a trigger for the development of occlusive clots in pulmonary microvessels. In this model of pulmonary embolism, DX-9065a $(10.0 \mathrm{mg} / \mathrm{kg}) \mathrm{im}-$ proved the mortality at $6 \mathrm{~h}$, but not at $1 \mathrm{~h}$, after initiation of venous thrombi. On the other hand, an intravenous bolus injection of heparin (300 units $/ \mathrm{kg}$ ) did not change the mortality even if the amount of heparin significantly prevented an occlusion by clots in the femoral vein. Current anticoagulant therapy displays limited efficacy. Clotbound thrombin is relatively resistant to heparin $[25,26]$. Direct thrombin inhibitors are able to prevent fibrinbound thrombin, but cannot inhibit new thrombin generation [27]. Indeed, our histological observations showed a large amount of embolism in the lung when the mouse was dead. Microembolism was also detected in surviving mice at $1 \mathrm{~h}$ after the initiation of venous thrombi. The increase of mortality in control mice could be caused by an enhancement of microembolism during the following $5 \mathrm{~h}$. During the above process, our findings indicated that inhibition of $\mathrm{FXa}$ is more effective than inhibition of thrombin, since prothrombin normally exists in the circulation and was immediately conversed by coagulation of FXa.

On the other hand, the pulmonary status of PAI-1-/mice evaluated $1 \mathrm{~h}$ after initiation of venous thrombosis was improved and the mortality was decreased compared with that of wild-type mice. These positive effects were not observed in PAI-1 ${ }^{-/}$mice treated with PAI-1. The above findings indicated that PAI-1 plays an important role in the events leading to embolism. Additionally, treatment with DX-9065a of PAI-1 ${ }^{-/}$mice markedly improved the survival ratio in pulmonary embolism. Therefore, the physiological importance of inhibitory action on acute pulmonary embolism in mice might be the following. First, induction of embolism directly damaged pulmonary vessels and the function of the lung immediately decreased following marked gasping. Coagulation and the fibrinolysis system play an important role in all types of thrombosis and embolism, not always only in the acute phase of pulmonary embolism. Second, microembolism gradually increases in surviving mice. During this process, inhibition of FXa could prevent the increase of embolism due to amplification of thrombin generation. Moreover, a lack of PAI-1 markedly enhances the effects of the FXa inhibitor.

It should be noted that antithrombotic and thrombolytic interventions might easily be complicated by hemorrhagic events. The amount of DX-9065a in this experiment did not significantly prolong the bleeding time in wild-type mice. The bleeding tendency was more pronounced in PAI-1 ${ }^{-/-}$mice when heparin, but not DX9065a, was given. It is well established in circulation that thrombin plays a key role in hemostasis. Amplification of the coagulation system by the prothrombinase complex should affect an increase in thrombogenesis. Moreover, the bleeding time of PAI-1-1- mice was not significantly prolonged as compared with that of wild-type mice. These findings indicate that under the condition of a lack of PAI-1 it is easy to get a sufficiently antithrombotic effect with DX-9065a without a bleeding risk.

In conclusion, coagulation of FXa plays a role in the amplification of pulmonary embolism and PAI-1 plays a key role in the development of embolism. Therefore, a dual inhibition of coagulation for FXa and PAI-1 significantly improved mortality in acute pulmonary embolism. These findings could represent useful information for clinical therapy.

\section{Acknowledgment}

This study was supported by Grants-in-Aid for Scientific Research on Priority Areas from the Ministry of Education, Science and Culture, Japan.

\section{References}

1 Anderson FA Jr, Wheeler HB, Goldberg RJ, Hosmer DW, Patwardhan NA, Jovanovic B, Forcier A, Dalen JE: A population-based perspective of the hospital incidence and casefatality rates of deep vein thrombosis and pulmonary embolism. The Worcester DVT Study. Arch Intern Med 1991;151:933-938.

2 Sutton GC, Hall RJ, Kerr IH: Clinical course and late prognosis of treated subacute massive, acute minor, and chronic pulmonary thromboembolism. Br Heart J 1977;10:1135-1142.
3 Kraaijenhagen RA, Haverkamp D, Koopman MM, Prandoni P, Piovella F, Buller HR: Travel and risk of venous thrombosis. Lancet 2000; 356:1492-1493.

4 Collen D, Lijnen HR: Basic and clinical aspects of fibrinolysis and thrombolysis. Blood 1991; 78:3114-3124.

5 Rifkin DB, Moscatelli D, Bizik J, Quarto N, Blei F, Dennis P, Flaumenhaft R, Mignatti P: Growth factor control of extracellular proteolysis. Cell Differ Dev 1990;32:313-318.
6 Kruger S, Haage P, Hoffmann R, Breuer C, Bucker A, Hanrath P, Gunther RW: Diagnosis of pulmonary arterial hypertension and pulmonary embolism with magnetic resonance angiography. Chest 2001;120:1556-1561.

7 Lang IM, Moser KM, Schleef RR: Elevated expression of urokinase-like plasminogen activator and plasminogen activator inhibitor type 1 during the vascular remodeling associated with pulmonary thromboembolism. Arterioscler Thromb Vasc Biol 1998; 18:808-815. 
8 Gallus AS: Thrombolytic therapy for venous thrombosis and pulmonary embolism. Baillières Clin Haematol 1998;11:663-673.

$\checkmark 9$ Herbert JM, Bernat A, Dol F, Herault JP, Crepon B, Lormeau JC: DX 9065A a novel, synthetic, selective and orally active inhibitor of factor Xa: In vitro and in vivo studies. J Pharmacol Exp Ther 1996;276:1030-1038.

-10 Flores J, Garcia-Avello A, Flores VM, Navarro JL, Canseco F, Perez-Rodriguez E: Tissue plasminogen activator plasma levels as a potential diagnostic aid in acute pulmonary embolism. Arch Pathol Lab Med 2003;127:310-315.

- 11 Bottiger C, Koch W, Lahn C, Mehilli J, von Beckerath N, Schomig A, Kastrati A: 4G/5G polymorphism of the plasminogen activator inhibitor-1 gene and risk of restenosis after coronary artery stenting. Am Heart J 2003;146: 855-861.

$\checkmark 12$ Roller RE, Schnedl WJ, Korninger C: Predicting the risk of restenosis after angioplasty in patients with peripheral arterial disease. Clin Lab 2001;47:555-559.

$\checkmark 13$ Kim KK, Flaherty KR, Long Q, Hattori N, Sisson TH, Colby TV, Travis WD, Martinez FJ, Murray S, Simon RH: A plasminogen activator inhibitor-1 promoter polymorphism and idiopathic interstitial pneumonia. Mol Med 2003; 9/1-2:52-56

14 Senno SL, Pechet L: Clinical implications of elevated PAI-1 revisited: Multiple arteria thrombosis in a patient with essential thrombocythemia and elevated plasminogen activator inhibitor-1 (PAI-1) levels: A case report and review of the literature. J Thromb Thrombolysis 1999;8/2:105-112.
15 Matsuno H, Kozawa O, Niwa M: Differential role of components of the fibrinolytic system in the formation and removal of thrombus induced by endothelial injury. Thromb Haemost 1999;81:601-604.

16 Hashimoto M, Onobayashi Y, Oiwa K, Giddings JC, Yamamoto J: Enhanced endogenous thrombolysis induced by a specific factor $\mathrm{Xa}$ inhibitor, DX-9065a, evaluated in a rat arterial thrombolysis model in vivo. Thromb Res 2002;106:165-168.

17 Nishida M, Matsuno H, Kozawa O, Ueshima S, Matsuo O, Collen D, Uematsu T: tPA, but not uPA, significantly affects antithrombotic therapy by a glycoprotein IIb/IIIa antagonist, but not by a factor Xa inhibitor. J Cardiovasc Pharmacol 2000;36:770-775.

18 Carmeliet P, Schoonjans L, Kieckens L, Ream B, Degen J, Bronson R, De Vos R, van den Oord JJ, Collen D, Mulligan RC: Physiological consequence of loss of plasminogen activator gene function in mice. Nature 1994;368:419424

19 Matsuno H, Uematsu T, Nagashima S, Nakashima M: Photochemically induced thrombosis model in rat femoral artery and evaluation of effects of heparin and tissue-type plasminogen activator with use of this model. J Pharmacol Methods 1991;25:303-317.

20 Matsuno H, Kozawa O, Okada K, Ueshima S, Matsuo O, Uematsu T: Plasmin generation plays different roles in the formation and removal of arterial and venous thrombus in mice. Thromb Haemost 2002;87/1:98-104.
21 Kawasaki T, Sato K, Sakai Y, Hirayama F, Koshio H, Taniuchi Y, Matsumoto Y: Comparative studies of an orally-active factor Xa inhibitor, YM-60828, with other antithrombotic agents in a rat model of arterial thrombosis. Thromb Haemost 1998;79:410-416.

22 Bdeir K, Murciano JC, Tomaszewski J, Koniaris L, Martinez J, Cines DB, Muzykantov VR, Higazi AA: Urokinase mediates fibrinolysis in the pulmonary microvasculature. Blood 2000;96:1820-1826.

23 Butte AN, Houng AK, Jang IK, Reed GL: Alpha 2-antiplasmin causes thrombi to resist fibrinolysis induced by tissue plasminogen activator in experimental pulmonary embolism. Circulation 1997;95:1886-1891.

24 Robinson BR, Houng AK, Reed GL: Catalytic life of activated factor XIII in thrombi. Implications for fibrinolytic resistance and thrombus aging. Circulation 2000;102:1151-1157.

25 Hogg PJ, Jackson CM: Fibrin monomer protects thrombin from inactivation by heparinantithrombin III: Implications for heparin efficacy. Proc Natl Acad Sci USA 1989;86:36193623 .

26 Weitz JI, Hudoba M, Massel D, Maraganore J, Hirsh J: Clot-bound thrombin is protected from inhibition by heparin-antithrombin III but is susceptible to inactivation by antithrombin III-independent inhibitors. J Clin Invest 1990;86:385-391.

27 Prager NA, Abendschein DR, McKenzie CR, Eisenberg PR: Role of thrombin compared with factor $\mathrm{Xa}$ in the procoagulant activity of whole blood clots. Circulation 1995;92:962967.
Effect of Xa Inhibitor on

Thromboembolism
Pathophysiol Haemost Thromb 2003/04;33:206-213 